\title{
Psychosexual Health of Married Nurses Working in Private \& Government Hospitals
}

\author{
Dr. Shikha Sharma ${ }^{1}$
}

Keywords: Psychosexual Health, Married Nurses, Private \& Government Hospitals

Health is a state of complete physical, mental and social well-being and not merely the absence of disease or infirmity. Women's health involves their emotional, social and physical well-being and is determined by the social, political and economic context of their lives, as well as by biology.

Health and performance are interdependent to each other. Good health is the foundation of performance. A healthy person will do better in every aspect of life, such as professional life, family life, marital life and sexual life etc.

Albeit everyone talks of women improvement today but the question is "Do we really feel concern about women and women's health?” Undoubtedly women have more pressure of work whether they are working or non-working, women have to face more problems due to various health problems such as physical, mental, family and sexual health.

Job conditions and multiple roles play an important part for women's health at midlife, Collins (2002).

Shift work influence the physical health of nurses, which in turn affect social and work related variables including family relations, formal and informal social participation, solitary activities, job performance and job related stress.

Schernhammer, Eva S., Laden Francine, \& Speizer, Frank E. (2003) suggested that working a rotating night shift at least three nights per month for 15 or more years may increase the risk of colorectal cancer in women.

Many married nurses experience considerable stress and burn out. These included, increases in workload and administration, time management, role conflict, lack of resources. Not having enough time for their personal and family life because of their unsystematic and unorganized profession they face lot of problems at home, which in turn increases conflicts among the family members like husband, in-laws etc.

${ }^{1}$ Clinical Psychologist at Geetamjali Medical College And Hospital, Udaipur.

(C) 2015 I S Sharma; licensee IJIP. This is an Open Access Research distributed under the terms of the Creative Commons Attribution License (http://creativecommons.org/licenses/by/2.0), which permits unrestricted use, distribution, and reproduction in any Medium, provided the original work is properly cited. 


\section{Psychosexual Health of Married Nurses Working in Private \& Government Hospitals}

Nurses attend to the emotional need of patients and their families, as well as undertake managerial responsibilities such as supervising junior staff. The demands of these roles at job as well as at home make them psychologically ill. They experiences high role stress manifested more symptoms of free floating anxiety obsessive neurotic depression hysterical neurosis, phobic anxiety and somatic anxiety.

Family health of the nurses is also affected by their shift work. As they are not able to concentrate on their family. Meeting with family demands is most detrimental to nurses emotional stability and sense of adequacy.

On the other hand, women's tendency to attach much to the marriage and home related activities make them susceptible to guilt and demands. In such situations, it is understandable that stress associated with meeting family demands would effect negatively a person's psychological well being.

Sexual health of married nurses is greatly affected because of stress that can lead to diminished sexual desire and inability to achieve orgasm in women. Long busy working hours develops fatigue in them and due to which interest in sex is lowered in them.

Fatigue and stress can also develop infertility among married nurses. If the sexual health is disturbed by some means other aspects of psychological well being are also greatly affected.

On the basis of review it seems that studies have been conducted on the various aspects of women health however very few attempts have been made to study women's total health that is sexual health, family health, marital health and professional health. It is inevitable to understand the health of women in the total prospect.

Realizing the paucity of research an attempt in the present research was made to study women's health in relation to the nature of organization and nature of family. The finding of the present research throws light on the various aspect of health of women. Besides this on the basis of the findings of the present research it will be possible to chalk out a suitable training program to improve quality of psycho-sexual life of nurses, which ultimately will assist nurses to lead every aspect of life in the most effective and efficient manner.

Macleod, John and Smith, George Davey, (1997) reported that job stress appears typically patterned among North American nurses, higher stress being associated with lower social position.

Escriba, Aguir V \& Fernandez, Sanchez R. (2000) in their study found that a higher level exposure to work stress factors lowers the psychological welfare among nursing staff.

Feskanich, D., Hastrup, J. L., Marshall, J. R., and Kawachi , I. (2002) in the study concluded that when responses to home and work stress were combined, there was an almost fivefold increase in risk of suicide among women in the high stress category. 
Mandira, Dhar (2002) in the study concluded that women doing multiple roles to cope with stress and anxiety involved and it is taking serious tolls on their mental and physical health.

\section{OBJECTIVES}

a.) To study Psycho-Sexual Health of married nurses working in private hospitals and government hospitals.

b.) To study Psycho-Sexual Health of married nurses working in relation to marital duration.

c.) To study Psycho-Sexual Health of married nurses working in relation to nature of family health.

\section{Tools/Materials}

\begin{tabular}{lll}
\hline \multicolumn{1}{c}{ Tools } & Developed By & Year \\
\hline P.G.I. Health Questionnaire N-1 & Verma, S.K. & 1985 \\
& Wig, N.N., and Prasad, D. & \\
Family Health Questionnaire & Researcher & 2003 \\
Coital Behavior Questionnaire & Mathur, C.N. and Jain, P. & 1986 \\
Mental Health Inventory & Jagdish, and Shrivastave, A.K. & 1978 \\
\hline
\end{tabular}

\section{METHOD}

\section{Sample}

The sample for the present study consisted of 200 married Nurses which were selected through purposive random sampling technique, Out of 200 Nurses, 100 Nurses belonged to Private Hospitals and 100 Nurses belonged to Government Hospitals. Out of 100 Private Nurses 50 Nurses belonged to Joint Families and 50 another Nurses belonged to Nuclear Families. Similar pattern distribution was adopted for Government Nurses.

\section{RESULT}

Observations collected on Psycho-Sexual Health variables have been statistically analyzed and presented under the following headings:
A) Family Health
B) Physical Health
C) Sexual Health
D) Mental Health 
Psychosexual Health of Married Nurses Working in Private \& Government Hospitals

Table A1, ANOVA For Occupation/Family and Family health.

\begin{tabular}{|l|l|l|l|l|l|}
\hline $\begin{array}{l}\text { Source of } \\
\text { Variation }\end{array}$ & SS & $\boldsymbol{d} \boldsymbol{f}$ & $\boldsymbol{M S}$ & $\boldsymbol{F}$ & Significance \\
\hline PJ/N & 310.005 & 1 & 310.005 & 12.4527 & $<0.01$ \\
\hline GJ/N & 17.405 & 1 & 17.405 & 0.699148 & NS \\
\hline Interaction & 41.405 & 1 & 41.405 & 1.663213 & NS \\
\hline Within & 4879.34 & 196 & 24.89459 & & \\
\hline Total & 5248.155 & 199 & & & \\
\hline
\end{tabular}

$\mathrm{PJ} / \mathrm{N}=$ Private Hospital, Joint/Nuclear Family.

GJ/N = Government Hospital, Joint/Nuclear Family.

' $F$ ' test was found significant at 0.01 level for private hospital nurses. But ' $F$ ' value was not found significant for government hospitals nurses. Interaction effect was also not found significant for Family Health.

Table A2, Marital duration and Family Health.

\begin{tabular}{|l|l|l|l|l|l|}
\hline Duration & N & Mean & SD & CR & Significance \\
\hline 5 Year & 80 & 27.09 & 4.72 & & \\
\hline & & & & 2.9 & $<0.01$ \\
\hline 10 Year & 120 & 25 & 5.5 & & \\
\hline
\end{tabular}

Table A4 indicates that critical ratio (CR) was found significant between marital age and family health at 0.01 level.

Table B1, ANOVA For Occupation/Family and Physical health.

\begin{tabular}{|l|l|l|l|l|l|}
\hline $\begin{array}{l}\text { Source of } \\
\text { Variation }\end{array}$ & SS & $\boldsymbol{d} \boldsymbol{f}$ & $\boldsymbol{M S}$ & $\boldsymbol{F}$ & Significance \\
\hline PJ/N & 796.005 & 1 & 796.005 & 40.76382 & $<0.01$ \\
\hline GJ/N & 335.405 & 1 & 335.405 & 17.17626 & $<0.01$ \\
\hline Interaction & 400.445 & 1 & 400.445 & 20.50699 & $<0.01$ \\
\hline Within & 3827.34 & 196 & 19.5272 & & \\
\hline Total & 5359.195 & 199 & & & \\
\hline
\end{tabular}

In the above table ' $F$ ' ratio was found significant at 0.01 level for nature of family (Nuclear / joint family) and private hospital. It was also found significant for nature of family and government hospital. Interaction was found significant. 
Table B2, Marital duration and Physical Health.

\begin{tabular}{|l|l|l|l|l|l|}
\hline Duration & N & Mean & SD & CR & Significance \\
\hline 5 Year & 80 & 11.17 & 5.56 & & \\
\hline & & & & 7.16 & $<0.01$ \\
\hline 10 Year & 120 & 5.87 & 5.56 & & \\
\hline
\end{tabular}

Significant difference was observed between marital duration and physical health. The mean score of women having marital duration of 5 years was 11.17 while it was 5.87 for the women with 10 years marital duration.

Table C1, ANOVA For Occupation/Family and Sexual health.

\begin{tabular}{|l|l|l|l|l|l|}
\hline $\begin{array}{l}\text { Source of } \\
\text { Variation }\end{array}$ & SS & $\boldsymbol{d} \boldsymbol{f}$ & $\boldsymbol{M S}$ & $\boldsymbol{F}$ & Significance \\
\hline PJ/N & 2842.58 & 1 & 2842.58 & 21.56601 & $<0.01$ \\
\hline GJ/N & 56.18 & 1 & 56.18 & 0.426225 & NS \\
\hline Interaction & 1372.88 & 1 & 1372.88 & 10.41573 & $<0.01$ \\
\hline Within & 25834.44 & 196 & 131.8084 & & \\
\hline Total & 30106.08 & 199 & & & \\
\hline
\end{tabular}

It is observed from table C1 that ' $\mathrm{F}$ ' ratio was found significant for nature of family and private hospital. However it was not found significant for nature of family and government hospital. Interaction was found significant.

Table C2, Marital duration and Sexual Health.

\begin{tabular}{|l|l|l|l|l|l|}
\hline Duration & N & Mean & SD & CR & Significance \\
\hline 5 Year & 80 & 71.95 & 11.65 & & \\
\hline & & & & 1.75 & NS \\
\hline 10 Year & 120 & 65.87 & 12.86 & & \\
\hline
\end{tabular}

C.R. was found no significant in the case of marital duration and Sexual Health.

Table D1, ANOVA For Occupation/Family and Mental health.

\begin{tabular}{|l|l|l|l|l|l|}
\hline $\begin{array}{l}\text { Source of } \\
\text { Variation }\end{array}$ & SS & df & MS & F & Significance \\
\hline PJ/N & 946.125 & 1 & 946.125 & 5.022877 & NS \\
\hline GJ/N & 2332.445 & 1 & 2332.445 & 12.3827 & $<0.01$ \\
\hline Interaction & 2278.125 & 1 & 2278.125 & 12.09432 & $<0.01$ \\
\hline Within & 36919.18 & 196 & 188.3632 & & \\
\hline Total & 42475.88 & 199 & & & \\
\hline
\end{tabular}


It is clear from the above table that analysis of variance was not found significant in the case of nature of family and private hospital. However it was found significant at 0.01 level for nature of family and government. Interaction was also found significant.

Table D2, Marital duration and Mental Health.

\begin{tabular}{|l|l|l|l|l|l|}
\hline Duration & $\mathbf{N}$ & Mean & SD & CR & Significance \\
\hline 5 Year & 80 & 170.16 & 14.37 & & \\
\hline & & & & 2.16 & NS \\
\hline 10 Year & 120 & 164.92 & 15.87 & & \\
\hline
\end{tabular}

CR was not found significant in the case of marital duration and mental health.

\section{DISCUSSION}

The findings of the present study revealed positive effect of marital duration on family health, mental health and physical health, but there was no effect of marital duration on sexual health. Psycho-sexual health was affected by nature of occupation.

Nurses are regarded in their family because this profession of nursing is viewed as respectable in society. In the earlier time the nursing profession was not considered as the dignified occupation their activities were judged as unhygienic by the people, but the current scenario has completely changed and the nursing profession is found one of the dignified and highly demanding occupation today whether, be a private or government sector health care services nurses are rendering their services to the society at their fullest. This attitude of society motivates the nurses to maintain the balance between family and profession, which ultimately resulted in not affecting their family health due to professional and other factor.

Nurses with 5 years duration had more problems as compare to nurses with 10 year durations. The more problems in the nurses with 5 years duration might be due to the number of responsibilities that is social, psychological, marital, child rearing and child birth along with psycho-sexual pressure as the time passes all kind of adjustment are made by women and she is able to cope with the existing demand of the family. Better family health in later years of marital life show the experience which a lady gets in view of leading a balance marital and family life similarly grown up children and matures husband wife relationship also work as an asset in maintaining a good family health. Spindola, (2004) observed that nurses prairies type of work they have, although they realize that their profession interferes in their everyday lives, as well as the interference of working in the family life, although nurses value the career, they are overburdened with the amount of tasks, pointing out the importance of the husband's role in the family life. 


\section{Psychosexual Health of Married Nurses Working in Private \& Government Hospitals}

Nurses were not able to take proper care of their physical health because of excess work pressure. They have to be alert at hospital, they have to work at home and take care of their children too. Therefore they do not get time for relaxation. These reasons, causes several physical problems like fatigue irritation depression anxiety, lack of sleep, lack of hunger, constipation, restlessness, emotional disturbance, fear of criticism and high blood pressure etc. Rosa, S.,(2004) reported that nurses suffered from Musculo-Skeleted disorders working in government hospitals suggest this that professional women are more prone to these problems.

Physical health of nurses with 5 years duration had more adjustment in the family problems as well as in the profession as compared to nurses with 10 years duration. The possible explanations for the more problems in the case of nurses with 5 years duration might be their being busy in rearing small children, adjustment with new environment with new family members. All these pressures affect their physical health.

In the case of nurses working in private hospitals nature of family did not influence the physical health. Nurses working in private sector are having low work pressure as they have a choice of working either in any one of the night, day or evening shifts. Which shows less physical problems. Cheng, Kawachi and Colditz, (2000) in their study concluded that adverse psychosocial work conditions were important predictors of poor functional physical health.

Condition of government hospitals nurses is not that good. They have work pressure because of scarcity of staff and large number of patients. These reasons cause fatigue, irritation, sleep disturbance and stomach problems etc.

Sexual Health of nurses working in private hospitals belonging to joint family was found more better as compared to nurses belonging to nuclear family. Nurses with 5 years duration had more problems as compared to nurses with 10 years duration.

Better sexual health of nurses belonging to joint family is very important indication of the fact that the importance of family can not be denied in making an individual effective in regard to every aspect of health. Joint family provides every kind of protection which prepare an individual to manage every aspect of life to live more lively. In joint family there are more numbers of helping hands. Nurses of nuclear family and private hospitals had more problems as compared to nurses of joint family and government hospitals. The problems such as pain during intercourse, less sexual desire, lack of sexual pleasure and pain at times of excretion were more reported as compared to nurses belonging to joint family and working government hospitals. Gupta, S. and Lynn, (1972) in their study found that women reached orgasm regularly psychological factors appeared to be the major reason for failure of orgasm by the wife and motherhood as the major factor which diminished the sex urge in married life.

Good Mental Health was not found in nurses working either in government or in private or hospitals belonging to joint or nuclear family. Roles of women are increasing as they have started working outside homes, which produced as additional amount of stress on them. Nurses live in more stressful condition psychologically which strain adaptive mechanism. Prolonged 
tension may produce psychological disorders, reported cry easily, tension, worry about small matters, irritation and aggression.

Mental health was found better in nurses who belonged to joint family in comparison to nurses belonging to nuclear family. Nurse belonging to joint family do not have much responsibilities, they do not have burden of family work as being by other family members, there for they are relatively more free which makes them more psychologically healthy.

Mental health was not affected by marital duration. Finding shows that nurses are having good mental health, positive self evaluation, perception of reality, good oriented attitude and environmental mentally strong and are able to make adjustment in any of the adverse condition. They are having self confidence, they are not afraid of adverse condition, have good decision making power, calmness, not afraid of their responsibilities and are satisfied with their work both at home and at work place. They are not dependent on others for these works and try to solve their own the problems by themselves. They are always encouraged to achieve their goals and they think that they are moving towards a specific goal and are having their own self identity. It seems that the training of nurses helps them to maintain mental health in every phase of marital life. Yamashita K, .(1997) their results suggested that the mental health of nurses who worked on surgical ward might suffer more than that of those who worked in internal medicine and those assigned to the elderly medicine.

\section{CONCLUSION}

The majority of women describe themselves only through the set of different social roles losing the contact with their inner needs and resources. A typical attitude was found in the women that lead to the inner disbalance of women and her exhaustion and losing of satisfaction. One of the main problem of the disbalance in the hyper-responsibility of women. Having the necessity to combine work, social and family life and her own personal needs take the last place. The pressure of the analyzed social models of "good wife", "good mother" support this attitude. These lead to the high level of life dissatisfaction, depression, sexual dissatisfaction, stress, high blood pressure, etc. on the other hand the necessity of responsibilities of family conflicts and even to the divorce due to the decreasing of value of the "family".

\section{REFERENCES}

Cheng, Kawachi \& Cilditz (2000), 'Association between psychosocial work characteristics and health functioning in American Women: prospective study, BMJ, 320:1432-1436.

Collins (2002), 'Work, Psychosocial Factor and Women’s Health at Midlife', Women Work and Health Abstract; 211.

Escriba, Aguir V \& Fernandez, Sanchez, R. (2000),' Work-related stress factors and the psychological well-being of hospital nurses', Institut Valencia d'Estudis en Salut Publica (IVESP); vol.23, no. 7-8, pp. 506-11. 
Feskanich, D., Hastrup, J. L., Marshall, J. R., and Kawachi, I. (2002), 'Stress and suicide in the Nurses' Health Study', Journal of Epidemiology and Community Health ; vol.56, pp. 9598.

Gupta, S. and Lynn (1972), 'A study of younger married women in different social contexts of occupational and family life, Human Relation’, Vol. 24, no. 6, pp.585-601.

Macleod, John and Smith, George Davey, (1997),American Journal of Epidemiology (2005), vol .162 no.11, pp.1133-1134.

Mandira, Dhar (2002), 'The deteriorating mental \& physical health', Women Work \& Health Abstract.

Rosa, S. (2004), 'Musculo-skeletal disorders in nurses and physiotherapists (Nr. 393)', Women Work \& Health Abstract; 168.

Schernhammer, Eva S., Laden Francine, \& Speizer, Frank E. (2003), 'Night-Shift Work and Risk of Colorectal Cancer in the Nurses' Health Study', Journal of the National Cancer Institute, Vol. 95, No. 11, pp. 825-828.

Spindola (2002), 'Women and Work Being, Mother and Nursing Professional'. Women Work \& Health Abstract; 259.

Yamashita K. (1997), 'Mental health of nurses--2 years follow-up', Sekisei Kouseiren Tsuwano Kyozon Hospital , Japan; vol.17, no. 4, pp. 64-8. 